\title{
The Jack Daniel's Experience: Communal Performances and the Marketing of Place
}

\section{Torben Huus Larsen}

University of Southern Denmark

\begin{abstract}
Since the 1950s Jack Daniel's has persistently marketed its whiskey as being synonymous with the values and ideals of the small Tennessee community of Lynchburg. Using black and white images of old men in overalls, sitting on wooden benches playing checkers, or other such unhurried activities, through advertisements, tours of the distillery, and even a line of Jack Daniel's clothes produced by Wrangler, the famous Tennessee whiskey employs images of the rural and the local in order to explore a romanticized past: a narrative used to signal a sense of anti-modernity and authenticity to its consumers. However, as the success of its marketing campaign has made Jack Daniel's an international tourist attraction, drawing in excess of a quarter of a million visitors annually, the identity of small-town Lynchburg has increasingly been entangled with the romanticized nostalgia of the Jack Daniel's ads.
\end{abstract}

Keywords: Jack Daniel's-marketing-place-tourism-narrative-LynchburgTennessee-the American South.

In 2008, for the first time in the brand's history, Jack Daniel's sold more whiskey abroad than it did on the American market. The company's global success is, at least in part, attributable to the celebrated ad campaign that, in spite of the company's position as a global multi-million dollar business, persistently has marketed the Jack Daniel's brand as indistinguishable from the small-town values and ideals of Lynchburg, Tennessee - the town where Jasper Newton "Jack" Daniel was born and where he began distilling the now famous whiskey in 1866 . Through highly stylized, historicized, 
and localized images of Lynchburg, in the course of the last half century, the Jack Daniel's campaign has successfully sold a distinctly Southern and, one might argue, rather stereotypical sense of place and history. Through the often used images of rustic Lynchburg, marketers of the famous Tennessee whiskey have actively sought to evoke notions of anti-modernity in order to appeal to a post-war American society increasingly dominated by mass-production.

But the Jack Daniel's campaign, I propose, has come at a cost to the town of Lynchburg. On the one hand, it seems that the community gradually has come to adopt and identify with the nostalgic narrative propagated by the ads. On the other hand, as thousands of annual visitors descend upon the town "with one traffic light" - a Jack Daniel's phrase which the Moore County Chamber of Commerce has adopted for its website-in search for that anti-modern experience, local businesses and promotional materials have tended towards reproducing the language used in the nostalgic and romanticized whiskey ads in order to keep the tourist dollars flowing. The case of Lynchburg should perhaps be seen as less than a text-book example of destination branding, since there seems to be little in the way of a coordinated attempt at branding the town other than as a setting for the whiskey ads. Rather, the frequent use of highly stylized representations of the local community and its residents for advertizing purposes seems gradually to have intertwined the company's marketing strategy with the town's sense of self. In what appears an almost Baudrillardian turn of events, the Jack Daniel's ad campaign that was designed around a romanticized version of life in Lynchburg, is now being mimicked by the very community it portrays. Consequently, upon visiting Lynchburg in the spring of 2007 I got the distinct impression of witnessing a communal performance that seemed to highlight a complex interaction between the marketing efforts of a global corporation, the aesthetics of place, and the formation of local identity.

The notion of anti-modernity, and of guarding something authentic and borderline sacred, is at the very heart of the Jack Daniel's/Lynchburg narrative. Today this hardly seems a surprising strategy as authenticity has become somewhat of a buzz-theme in modern market research. Gilmore and Pine have noted that consumers in the experience economy increasingly view the world "in terms of real and fake" (Gilmore and Pine 1) and products in terms of the experience that it might grant them. Similarly, in their book The Soul of the New Consumer: Authenticity - What we Buy and Why in the New Economy, David Lewis and Darren Bridger-from the interna- 
tional consumer research firm the David Lewis Consultancy - have argued that in order to turn a profit in, what they have termed, the new economy, companies will have to communicate a sense of genuineness to the new consumer. Individualistic, informed, and involved, but pressed for time, attention, and trust, the new consumer is a product of, and accustomed to, the mechanisms of modern consumer society, and is furthermore on a constant quest for authenticity. Thus, only the companies that manage to purvey a sense of trustworthiness, and to do so in an accessible way, will ultimately survive in the new market (Lewis and Bridger).

Such analyses are valid and vital in a largely consumer-based economy where products have become vehicles for a new form of staged authenticity. Certainly, in the past twenty years the idea of authenticity has fuelled a wide range of modern marketing strategies seeking to sell anything from tourist experiences to clothing, furniture, and ethnic and organic foods. But although the new consumer may be a recent development, the paradoxical unease with consumption is not. Since the Jack Daniel's campaign was first launched in 1954 the idea of authenticity has been central to its popular appeal. The campaign strategy was adopted after an article in the magazine True depicted the distillery and the town of Lynchburg as examples of pre-modern places where the visitor might still experience a historic America that was rapidly disappearing elsewhere. Realizing that the article had hit a popular nerve, and seeking to shift from the upper-class segment to the post-war era's rapidly expanding middle class, the company's new ad agency, Gardner Nelson, was quick to adopt the small-town-that-timeforgot narrative as the central metaphor of their new campaign (Holt 368).

The postcards campaign, as it became known due to the ads' down-home tone of voice and the fact that they seemed to address the nation from the small township of Lynchburg in Tennessee, consisted of a series of black and white images featuring people from the local community. The photographs typically showed old and weathered Lynchburg residents in overalls sitting on wooden benches playing checkers, or participating in other such unhurried activities. The advertisements were created to appeal broadlyalthough presumably the target group consisted mainly of white males - by playing on a nostalgic longing for the supposed simplicity of the past. One ad from the late 1980s featured a black and white photograph of puppies being sold from the back of a pick-up truck along with the text: "There aren't many towns where coonhound pups are sold on Main Street. But Lynchburg, Tennessee, is one" ("Media Business"). The focus on a slower 
pace, social coherence, and community values corresponded to idealized depictions of an agrarian South that served as an exponent of just such anti-modernity. Setting up an imagined place where residents supposedly resisted the rampant capitalism and increasing social fragmentation of the 1950 s and 1960 s, the postcards campaign soon proved a success.

By playing on a sense of place, and rhetoric evocative of traditions and history, Jack Daniel's has thus spent the last half century communicating that elusive sense of authenticity to its consumers. As Ted Simmons, CEO of Arnold Worldwide-St. Louis, the advertising agency in charge of the campaign today, explains: "Jack Daniel's advertising has always been rooted in the authenticity and timelessness of Lynchburg, its people and how the product is made" ("Jack Daniel's Celebrates"). But that rootedness comes from more than just the historic connection between town and product. It is a deliberate strategy to give consumers the product and the experience that they want. As noted in an article in The New York Times: "The familiar magazine ads chronicle the life and times of Lynchburg, Tenn., the bucolic town where Jack Daniel's has been distilled since 1866. With their nostalgic photographs and folksy copy, the ads would surely be sepia-tinted were they not already black-and-white."

In 2004 the brand ventured into the manufacturing of western-style clothes and accessories including belt buckles, cowboy hats, wallets, and watches. Having already tapped into the popular association between whiskey and the Wild West by sponsoring Professional Bull Riders and Professional Rodeo Cowboys Association events, Jack Daniel's sought to expand its market share beyond the world of the rodeo, by adding a clothing line produced by Wrangler ("Jack Daniel's Celebrates"). And according to Jack Daniel's brand director John Hayes, it was a logical move considering that cowboys "would be more likely to drink Jack Daniel's than the average American," and that whiskey had "always been perceived as a drink with a lot of masculinity to it" ("Jack Daniel's Whiskey"). Whether such claims are true or merely based on popular Hollywood stereotypes of life on the frontier, the cowboy narrative certainly contains the same sort of simple living ideology that runs through most of the brand's advertisements. In that sense, the Jack Daniel's marketing strategy is not unlike the campaign that propelled Marlboro cigarettes from being a brand in crisis in the 1940s to a dominating factor within the industry. Just as the Lynchburg in Jack Daniel's ads apparently exists in a temporal vacuum where little changes, so the Marlboro campaign, with its familiar iconography of the lonesome, 
self-contained Marlboro Man, has fashioned a stylized and romanticized version of the American West, called Marlboro Country, a mythic landscape forever untouched by progress or industry.

Professor of marketing Douglas B. Holt sees more than a fleeting connection between the Jack Daniel's campaign and the American frontier mythology. In his study of the Jack Daniel's ad campaign as an example of brands as ideological parasites, Holt argues that Jack Daniel's specifically sought to tap into the anti-modernity of the frontier ideology when it shifted to its Lynchburg strategy. Pointing to the gunfighter myth's centrality to American culture, Holt connects the popularity of the postcards campaign with the frontier narrative, further arguing that whiskey is a drink that is historically linked to the frontier experience and to representations of that part of American history (Holt 360).

Holt's argument about branding processes and the ideologies that inform them is highly relevant, and he is right in pointing out that the pre-modern image has been central to making customers believe that in a time of mass-production and suburban conformity Jack Daniel's was the link to a forgotten past. But I disagree with Holt that the ideological source of the postcards campaign is the frontier narrative. Rather, the Jack Daniel's campaign is deeply rooted in the perceived rusticity of the late nineteenth and early twentieth-century South. Not only does the recent move towards strengthening the brand's image within the consumer segment traditionally attracted to Wrangler and rodeos suggest that the frontier ideology was not at the heart of the brand's original strategy, but whereas the frontier narrative revolves around social reinvention in a landscape traditionally perceived as being void of history, the Jack Daniel's ads, as part of a Southern agrarian narrative, have always emphasized tradition, history, and an overpowering sense of place.

And it is precisely the successful evocation of a sense of place and tradition that has worked wonders around the world. Although there are differences in the extent to which rural Lynchburg is used in the ads - in places like India and China, where many come from poor and rural backgrounds, customers might not find the rustic imagery as appealing as e.g. British consumers - the central message of small-town authenticity is received and understood globally. According to Director of International Marketing Partners, Allyson Stewart-Allen, the small-town imagery and the consistent focus on craftsmanship and intimacy may even have meant that the brand has been less likely "to experience boycotting from overseas markets" (Kiley). 
When asked about Jack Daniel's a Chinese consumer noted that he liked "how it's handcrafted and all comes from this one special place" (Kiley).

The experience of authenticity is not merely cultivated through the ads, it is also a dominant theme in the distillery tour which draws thousands of international visitors to Lynchburg every year. The tour, like the ad campaign, began in 1954 and focuses on the same anti-modernity themes. As historian Mark Weiner suggests, the tour can be divided into two parts: one that focuses on the "history of the consumer artifact" and another that "explores a past external to the product itself-in this case, the regional past, the nostalgic past of old Tennessee" (Weiner 231-232). Before the tour, tourists gather in the recently built 16,000 square-foot Visitor Center. Built to match the brand's rustic image, the center is full of displays showcasing the history and philosophy of Jack Daniel's. Here visitors can gaze at old tools, an antique whiskey delivery truck, and even a checkers board placed on a whiskey barrel with two chairs and an inscription explaining that the game, like distilling whiskey and like life in Lynchburg, is all about patience and allowing things to take their time. As the tour begins, visitors are led into a small theatre, where a short 7-minute video presentation introduces the Jack Daniel's brand in the familiar terms, opening with a shot of pastoral surroundings complete with a farm and a corral with a couple of horses. The rest of the tour exposes the visitors to the same message as they walk over the distillery grounds. There they can admire an old fire engine, the handcrafted wooden barrels where the whiskey is stored, the hollow from which the cool water for the whiskey-making process springs, and even Jack Daniel's old office complete with what, supposedly, are the original dusty account books. Emphasizing an adherence to history and traditions, even the guides are a part of the narrative that is being told. Performing as, and conforming to, a stereotypical "good ol' boy" persona, they embody the easy-going Southern charm, humor, and laid-back attitude that is central to representing the Jack Daniel's brand. Recently the company absorbed the regionally famous Miss Mary Bobo's Boarding House, a Southern-style restaurant that opened in 1908 when Miss Mary Bobo took over the historic Salmon Hotel. During my own visit, lunch at the famous restaurant became an almost logical conclusion of the tour, further cementing the association between the local and the distillery.

The popularity of the Jack Daniel's ad campaign has turned Lynchburg into a tourist experience, putting pressure on the small community to deliver according to tourist expectations and extending the performance beyond 
the distillery and into the streets. Wherever one ventures in Lynchburg, the Jack Daniel's narrative is visible. Almost every store in the historic town square sells a mixture of antiques and Jack Daniel's related souvenirs. Old-timey rocking chairs and checkers boards, the same props displayed at the Jack Daniel's Visitor Center and prominently featured in the advertisements, further the fusion of the communal and the corporate narrative. Likewise, on the local Chamber of Commerce website, Lynchburg is described as an "old fashioned town, the likes of which you may have thought no longer existed," a place where life in general "moves at a slower pace" (Moore County). Although created by the chamber of commerce, the website features none of the usual boasts about progress or economic opportunity designed to attract new industry to the area. On the contrary the text sounds like something that might have been copied out of the black and white whiskey ads. Another example is the Harley Davidson dealership that recently opened and which also features an "About Lynchburg" section on its website. Here the text dwells, once again, on that familiar description of Lynchburg as "a town that is so small that it has only one traffic light." The text goes on to note that in the absence of alcohol-Lynchburg is located in a dry county - the town has found other ways of keeping tourists busy, that is "if you're in the mood to take it slow." And similarly The Lynchburg Gazette, a tourist brochure in the form of a local newspaper, promotes the anti-modern image with articles such as "Slow Down a Bit, Sit, Whittle and be a Part of the Town" (Bell).

The impact of the Jack Daniel's advertisements on life in Lynchburg becomes even more apparent when considering the story of Mr. Herb Fanning, a local man who became so famous after appearing in a number of Jack Daniel's ads that he became known as the unofficial mayor of Lynchburg. In 2004, during the celebration of the ad campaign's $50^{\text {th }}$ anniversary, Jack Daniel's even put up a statue of Fanning in the town square, a tribute not only to the man himself and to the ad campaign, but also to the interplay between town and company through marketing ("Jack Daniel's Celebrates").

Naturally, the image of the isolated small Southern community that modernity has passed by is problematic on several levels. As Weiner argues, "it would be a mistake to consider the town outside of its interaction with national culture. Just as the traditions of Southeast Asian islands have been irreparably altered by the influx of western visitors and anthropologists, so the town of Lynchburg, and the Jack Daniel's distillery, exhibit the imprint 
of dialectic social dynamics" (Weiner 230). The fiction of a small isolated community is precisely that: fictional. Lynchburg is dependent on the jobs as well as the tax and tourist dollars generated by Jack Daniel's, and consequently seems willing to conform to the images of rural idyll that are propagated by the ads and which tend to guide the expectations of the many visiting tourists. Such cultivated rusticity naturally clashes with the reality of modern tourism. According to the Jack Daniel's website more than one quarter of a million yearly visitors find their way to the town where the famous whiskey is made. The studiously rustic Visitor's Center with rocking chairs on the porches, creates an ideal atmosphere for relaxing in the shade before and after the tour, but sitting on the porch also creates a heightened awareness of the camera the visitor is carrying; of the tourists in front of the building posing for group shots; and even of the number of high-speed computer stations set up inside of the air-conditioned center that allow visitors to log on to the Jack Daniel's website and register with name, age, and country, supplying the company with valuable marketing information. Calling the distillery a "theme park wrapped around a production plant," as one reporter has done (Cone), might be exaggerating the point, but much like the nearby theme park Dollywood, both Lynchburg and Jack Daniel's are highly self-conscious about their anti-modern image, and both town and brand rely heavily on a cultural iconography that appeals to urban Americans anxious about the hurriedness of their own lives.

The nostalgic narrative furthermore ignores the continued interaction between Lynchburg and the outside world. The Jack Daniel's brand is in fact owned by the Louisville, Kentucky, based Brown-Forman Corporation which is one of the nation's largest producers of wine and spirits. BrownForman aggressively protects its best-selling brand, and in 1982 sued 13 businesses in Gatlinburg for selling unauthorized reproductions of the distillery's trademark ("Daniel Distillery Suing"). In fact, Jack Daniel's is a far more modern and sophisticated operation than it wants visitors to believe. The actual bottling takes place, not in the old warehouse full of wooden barrels that visitors see on the tour, but in an automated bottling facility a couple of miles away (Cone). The narrative also conceals the fact that the heart of the Lynchburg community is in fact a global multimillion dollar industry that, being a major local employer, has had to make unpopular decisions, as when in 1985 it laid off more than 30 workers as the result of a miscalculation (Weiner 234). But as a plaque at the nearby Jack Daniel's visitors' center notes, there is no reason to spoil a good story with facts. 
In the introduction to his study of tourism in the American West, Devil's Bargains, Hal Rothman notes that often "regions, communities, and locales welcome tourism as an economic boon, only to find that it irrevocably changes them in unanticipated and uncontrollable ways" (10). This seems somewhat descriptive of what has happened in Lynchburg, although the adoption of the Jack Daniel's narrative seems to have been a less than mindful decision. As the Jack Daniel's brand has been tied to the imagined values of the small community, so Lynchburg's self-image has become inextricably connected with the whiskey advertisements and the nostalgic tale they tell. Thus "haunted, not by reality, but by those images we have put in place of reality" (Boorstin 6), from a visitor's perspective the carefully cultivated images of Southern idyll now seem to dictate the community's future.

When I visited Lynchburg I could not help but be reminded of the Borges fable "On Exactitude in Science" where cartographers create a map of the empire the same size as the empire itself. Finding the map useless, however, the following generations discard it, leaving its tattered remains to be "inhabited by Animals and Beggars" (Borges 325). Through its advertisements the Jack Daniel's brand has created an idealized copy of Lynchburg. But, as opposed to the Borges tale, the copy of Lynchburg has superseded the actual town, leaving its inhabitants to occupy a hyper-reality born of a successful marketing strategy.

\section{Bibliography}

Bell, Kimberley. 2009. "Slow Down a Bit, Sit, Whittle and be a Part of Town." The Lynchburg Gazette. Web.

Boorstin, Daniel. The Image: A Guide to Pseudo-Events in America. New York: Vintage Books, 1992. Print.

Borges, Jorge Luis. 1998. "On Exactitude in Science." Collected Fictions. Trans. Andrew Hurley. London: Penguin Books, 1998. Print.

Cone, Edward. "Whiskey, Neat." Baseline (April 1, 2003). Web.

"Daniel Distillery Suing Over Trademark Use." The Associated Press (February 3, 1982). Print.

Gilmore, James H. \& B. Joseph Pine II. Authenticity: What Consumers Really Want. Cambridge, MA: Harvard Business School Press, 2007. Print.

Harley Davidson, Lynchburg, TN website. "About Lynchburg". Web.

Holt, Douglas B. "Jack Daniel's America: Iconic brands as ideological parasites and proselytizers." Journal of Consumer Culture 6:3 (2006): 355-377. Print.

"Jack Daniel's Celebrates 50 Years of Legendary Advertising; Celebration Includes Statue Unveiling in Lynchburg, Tennessee." Business Wire (September 9, 2004). Print. 
The Jack Daniel's website. "Exploring Lynchburg." Web.

"Jack Daniel's Whiskey now making Western clothes to boost brand." The Associated Press State \& Local Wire (January 15, 2004). Print.

Kiley, David. “Jack Daniel's International Appeal.” Business Week (October 10, 2007). Web. Lewis, David and Darren Bridges. The Soul of the New Consumer: Authenticity-What We Buy and Why in the New Economy. London: Nicholas Brealing Publishing, 2000. Print.

"The Media Business: Advertising; Jack Daniel's Strategy is Turning 35." The New York Times (July 20, 1989). Print.

Moore County Chamber of Commerce website. "Home." Web.

Rothman, Hal. Devil's Bargains: Tourism in the Twentieth Century American West. Lawrence, KS: University Press of Kansas, 1998. Print.

Weiner, Mark. "We Are What We Eat; or, Democracy, Community, and the Politics of Corporate Food Displays.” American Quarterly 46:2 (1994): 227-250. Print. 